\title{
O AGRAVAMENTO DAS DESIGUALDADES SOCIAIS NA PANDEMIA DO CORONAVÍRUS SARS-COV-2 E A DIMENSÃO SOCIAL DA SUSTENTABILIDADE
}

\author{
AGGRAVING SOCIAL INEQUALITIES IN THE CORONAVÍRUS SARS-COV-2 \\ PANDEMIC AND THE SOCIAL DIMENSION OF SUSTAINABILITY
}

Ana Carolina Couto Matheus*

\begin{abstract}
RESUMO
O objeto da pesquisa é abordar que a pandemia do Coronavírus Sars-Cov-2 ou Covid-19 representa uma doença que tem assustado a população mundial, em razão da sua letalidade, bem como pelo rápido contágio. Em muito pouco tempo a referida pandemia contaminou grande parte da população mundial, como nenhuma outra doença, transformando-se em um enorme problema global de saúde pública, evidenciando problemas econômicos e sociais já conhecidos. Atualmente vivemos o surto da referida pandemia e ainda não há uma noção precisa da real dimensão da referida doença. Faltam respostas para tantas dúvidas. O objetivo geral da pesquisa em tela é verificar se a pandemia do Coronavírus impactou na dimensão social da sustentabilidade ao elevar os índices de desigualdades sociais. Será utilizado o método indutivo, a fonte de pesquisa bibliográfica, as técnicas do referente, da categoria, do conceito operacional e do fichamento.
\end{abstract}

Palavras-chave: Pandemia Sars-Cov-2 ou Covid-19. Desigualdade social. Dimensão social da sustentabilidade.

\begin{abstract}
The object of the research is to approach that the Coronavirus Sars-Cov-2 or Covid-19 pandemic represents a disease that has frightened the world population, due to its lethality, as well as its rapid contagion. In a very short time, this pandemic contaminated a large part of the world's population, like no other disease, becoming a huge global public health problem, evidencing known economic and social problems. We are currently experiencing the outbreak of the aforementioned pandemic and there is still no precise notion of the real dimension of the aforementioned disease. There are no answers to so many questions. The general objective of the research on screen is to verify if the Coronavirus pandemic has impacted the social dimension of sustainability by raising the levels of social inequalities. The inductive method will be used, the source of bibliographic research, the techniques of the referent, category, operational concept and filing.
\end{abstract}

Keywords: Sars-Cov-2 or Covid-19 pandemic. Social inequality. Social dimension of sustainability.

Artigo submetido em 02 de agosto de 2021 e aprovado em 24 de janeiro de 2022.

\footnotetext{
* Doutora em Ciência Jurídica pela UNIVALI-SC. Mestre em Direito pela UNIPAR-PR. Especialista em Direito Tributário pela UnP-RN. Pós-Graduada em Direito Constitucional pela UVB-SP. Graduada em Direito pela TOLEDO-SP. Professora Adjunta IV do CCJSA da Ufac-AC. Coordenadora do Núcleo de Prática Jurídica e Estágios do Curso de Direito da Ufac. Coordenadora e Professora do Curso de Pós-Graduação do CCJSA da Ufac. Orientadora. Conferencista. Conselheira Editorial. Pesquisadora. Advogada. Consultora Jurídica. E-mail: ana.matheus@ufac.br.
} 


\section{INTRODUÇÃO}

Atualmente a pandemia do Coronavírus Sars-Cov-2 ou Covid-19 assola a humanidade. Trata-se de uma doença causada pelo novo Coronavírus, uma espécie de vírus que causa grave infecção respiratória, caracterizada por uma enorme velocidade de contágio.

A referida pandemia do novo Coronavírus impactou profundamente a população global, no sentido de ter causado enormes prejuízos não só em relação à saúde pública, mas também nas questões sociais e econômicas.

Muitos países, no intuito de combater ou reduzir as taxas de transmissão da Covid-19, adotaram o isolamento social, fecharam o comércio e a prestação de serviços, mantendo aberto e funcionando, em caráter de urgência, apenas os serviços considerados essenciais. Esta iniciativa foi relativizada, pois é extremamente difícil paralisar a economia durante muito tempo, o que poderia provocar uma recessão enorme.

A partir do retorno às atividades normais, aconteceu um novo surto da pandemia do novo Coronavírus e muitos países precisaram novamente parar as atividades consideradas não essenciais e manter o isolamento social. É óbvio que as referidas medidas impactaram diretamente nas questões sociais e econômicas de forma diferente pelo mundo.

A pesquisa em testilha está associada à verificação de um impacto na dimensão social da sustentabilidade devido ao aumento ou não das desigualdades sociais em razão ao novo Coronavírus. Desta forma, o objetivo geral da pesquisa em epígrafe é verificar se a pandemia do Coronavírus impactou na dimensão social da sustentabilidade ao elevar os índices de desigualdades sociais.

O questionamento a seguir representa o problema central da pesquisa, a saber: o novo Coronavírus Sars-Cov-2 impactou na dimensão social da sustentabilidade em decorrência do aumento na desigualdade social?

Para responder ao questionamento acima formulado, a pesquisa em tela foi organizada em três partes. A primeira parte caracteriza o novo Coronavírus Sars-Cov-2 e retrata a pandemia da Covid-19. A segunda parte da pesquisa analisa as dimensões da sustentabilidade, em especial a dimensão social da sustentabilidade. A terceira parte da pesquisa destaca o aumento da desigualdade social no contexto da pandemia da Covid-19.

A pesquisa é desenvolvida conforme um esquema conceitual que conferiu um instrumental teórico articulado à problemática, destacando a relevância social global da temática.

O método indutivo foi utilizado na fase de investigação e no tratamento dos dados foi utilizado o método cartesiano. Nas distintas fases da pesquisa foram acionadas as técnicas do referente, da categoria, do conceito operacional, da pesquisa bibliográfica e do fichamento. $\mathrm{O}$ desenvolvimento do tema pautou-se pela persecução dos objetivos gerais e específicos que nortearam a produção. A pesquisa se encerra com as considerações finais e consubstancia o resultado dos achados, findando por confirmar a hipótese inicialmente concebida.

\section{O NOVO CORONAVÍRUS SARS-COV-2}

Em 2020 o mundo conheceu o novo Coronavírus Sars-Cov-2 e a pandemia da Covid19. Em 2021 o mundo continua convivendo com esta pandemia e as consequências dela advindas.

Trata-se de uma doença causada pelo novo Coronavírus, uma espécie de vírus que causa sérias infecções respiratórias. Desde 1937 os cientistas estudam os Coronavírus em seres humanos, somente a partir de 21 de dezembro de 2019 foi descoberto em Wuhan, na China, o novo coronavírus, conforme dados retirados na página do Ministério da Saúde, disponível em: https://coronavirus.saude.gov.br/. Acesso em: 2 ago. 2021. 
Artigo: O Agravamento das Desigualdades Sociais na Pandemia Do Coronavírus Sars-Cov-2 e a Dimensão Social da Sustentabilidade

Em 30 de janeiro de 2020, após o rápido aumento de casos do novo Coronavírus na República Popular da China e a transmissão para diversos outros países, a Organização Mundial da Saúde caracterizou a doença como uma emergência de saúde pública de importância internacional.

Apenas em 11 de março de 2020 a doença provocada pelo novo Coronavírus foi considerada pandemia pela Organização Mundial da Saúde, segundo dados obtidos na Folha informativa - Covid-19, disponível em: www.paho.org/bra/index.php?option=com_content \& view=article\&id=6101:covid19\&Itemid $=875$. Acesso em: 3 ago. 2021.

O conceito de pandemia está relacionado à distribuição geográfica de uma doença e não à gravidade dela. A referida denominação reconhece que no momento existem surtos de novo Coronavírus Sars-Cov-2 em diversos países do globo.

Em 11 de março de 2020, Tedros Adhanom Ghebreyesus, Diretor-Geral da Organização Mundial da Saúde, fez um pronunciamento explicando que "pandemia não deve ser usada de forma descuidada ou leviana. É uma palavra que, se mal empregada, pode despertar medo irracional ou a aceitação injustificável de que a luta acabou, levando a sofrimento e mortes desnecessárias" (BBC NEWS, 2020).

No contexto mundial, não se trata da primeira pandemia. Infelizmente, em nível global, a humanidade já precisou passar por algumas pandemias, que necessitaram de uma "resposta articulada tanto de governos nacionais e internacionais para seu combate" (UJVARI, 2011, p. $37)$.

Por exemplo, Costa e Hamann (2016, p. 11) destacam as pandemias da gripe espanhola de 1918 e 1920; a gripe asiática em 1957; a gripe de Hong Kong de 1968; a gripe russa de 1977 , causada por vírus influenza A (H1N1) de origem suína; a gripe aviária de 2003; a gripe A (H1N1) de 2009.

Além das pandemias, alguma vezes foram declaradas emergência de saúde pública de importância internacional, como destaca a ONU (2021) em 5 de maio de 2014, relativa à disseminação internacional de poliovírus; em 8 de agosto de 2014, referente ao surto de ebola na África Ocidental; em 1 de fevereiro de 2016, sobre o zika vírus e o aumento de casos de microcefalia, bem como outras malformações congênitas; e em 18 de maio de 2018, relativo ao surto de ebola na República Democrática do Congo.

O novo Coronavírus Sars-Cov-2 rapidamente foi disseminado ao redor do mundo, acarretando graves crises, bem como duas ondas de infecção respiratória em diversos países, inclusive o Brasil.

O aumento populacional acarreta a transmissão do novo Coronavírus, pois aproxima as pessoas, favorecendo o contágio deste tipo de infecção respiratória. A facilidade e o acesso das passagens aéreas, os inúmeros meios de transporte e principalmente a globalização tornam possível que o novo Coronavírus facilmente ultrapasse barreiras e esteja presente em diversos países, permitindo o rápido contágio, inclusive de variantes como a Delta e a Gama, entre outras.

Para evitar a contaminação de sua população, alguns países adotaram o isolamento social. No Brasil foi nesse sentido a recomendação do Ministério da Saúde, entretanto cada governador e prefeito teve autonomia para regulamentar da melhor forma como seria o isolamento.

Foram tomadas várias medidas com o objetivo de diminuir o contágio do novo Coronavírus Sars-Cov-2, como o uso de máscaras para cobrir o nariz e a boca, o fechamento do comércio, a redução ou até a proibição na circulação de pessoas e veículos, o fechamento de escolas, o fechamento de igrejas e templos, a proibição de festas, confraternizações e eventos em geral, a proibição de utilizar a praia, as praças e demais locais públicos a fim de evitar 
aglomerações, ou seja, uma grande solicitação para que os cidadãos permaneçam isolados em suas residências. Trata-se de uma enorme paralisação das atividades sociais e econômicas.

$\mathrm{O}$ isolamento social e a paralisação das atividades econômicas impactaram profundamente na sociedade e na economia, sem data para acabar, porque a pandemia continua e o objetivo das políticas públicas é preservar a vida. Portanto, a pandemia do novo Coronavírus Sars-Cov-2 e suas consequências continuam impactando na sociedade e na economia, ultrapassando as fronteiras entre os países.

\section{A SUSTENTABILIDADE SOB O ENFOQUE DA DIMENSÃO SOCIAL}

A sustentabilidade objetiva "atender as necessidades da geração presente e das futuras, de tal forma que o capital natural seja mantido e enriquecido em sua capacidade de regeneração, reprodução e coevolução" (BOFF, 2012, p. 107).

\footnotetext{
El paradigma actual de la Humanidad es la sostenibilidad. La voluntad de articular una nueva sociedad capaz de perpetuarse en el tiempo en unas condiciones dignas. El deterioro material del planeta es insostenible, pero también es insostenible la miseria y la exclusión social, la injusticia y la opresión, la esclavitud y la dominación cultural y económica (REAL FERRER, 2012, p. 319).
}

A sustentabilidade foi construída a partir do tripé dimensional ambiental, econômico e social. Na concepção de Canotilho (2010), a "dimensão tridimensional", realizada em 2000, com enorme influência da Declaração do Milênio, proclamou a Declaração e Objetivos do Milênio para o Desenvolvimento.

Diversos autores vislumbram outras dimensões da sustentabilidade. Freitas (2012) vislumbra cinco dimensões, a saber: ambiental, econômica, social, jurídico-política e ética. Dimensões "intimamente vinculadas, componentes essenciais à modelagem do desenvolvimento. De fato. Condicionam-no. Moldam-no. Tingem-no. Humanizam-no. Ecologizam-no. Fazem-no duradouro, continuado, sinergético, estimulante, inclusivo e vinculante" (FREITAS, 2012, p. 67).

Sobre a dimensão jurídico-política, Freitas (2012, p. 19) impõe ao Estado que garanta ao povo a tutela jurídica do direito a um meio ambiente saudável, tanto para a presente quanto para as futuras gerações.

Quanto à dimensão ética da sustentabilidade, Jamieson (2010, p. 7) afirma que "existe de fato o dever ético indeclinável e natural de sustentabilidade ativa, que não instrumentaliza predatoriamente, mas intervém para restaurar o equilíbrio dinâmico".

Sachs e Vieira (2007) vislumbram oito dimensões da sustentabilidade, a saber: social, cultural, ecológica, ambiental, territorial, econômica, política-nacional e política-internacional.

Conforme o entendimento de Cruz e Bodnar (2012, p. 112) a sustentabilidade é um paradigma que induz o direito à medida que sistematiza normas protetivas do ambiente para além da ciência jurídica e em escala global, tendo como base forte o meio ambiente, vislumbram a sustentabilidade em múltiplas dimensões que incluam as variáveis ecológica, social, econômica e tecnológica.

Para Real Ferrer (2012, p. 320), o direito à sustentabilidade é pensado para resolver problemas globais, visualiza dimensões que estão além do triângulo ambiental, econômico e social. Nesse sentido, o autor acredita que a inteligência humana individual e coletiva acumulada e multiplicada poderá assegurar um futuro mais sustentável.

A sustentabilidade é concebida em suas múltiplas dimensões, mesmo não existindo uniformização conceitual do seu termo parece evidente, pela vasta literatura que envolve a matéria, que ela é um "valor" (FREITAS, 2014, p. 32), um "princípio" (SILVA, 2010; CRUZ; 
Artigo: O Agravamento das Desigualdades Sociais na Pandemia Do Coronavírus Sars-Cov-2 e a Dimensão Social da Sustentabilidade

GLASENAPP, 2014; FREITAS, 2014; BOSSELMANN, 2015) e um "direito fundamental" (COIMBRA, 2017).

A pesquisa em testilha adota a classificação dimensional da sustentabilidade categorizada por Freitas (2012). A dimensão ambiental da sustentabilidade para Silva (2007, p. 18) "é a interação do conjunto de elementos naturais, artificiais e culturais que propiciem o desenvolvimento equilibrado da vida em todas as suas formas".

Segundo o entendimento de Garcia (2011) a dimensão econômica da sustentabilidade trata do desenvolvimento da economia com a finalidade de gerar melhoria na qualidade de vida das pessoas, com padrões que contenham o menor impacto ambiental possível. O "desenvolvimento harmônico da economia e ecologia que devem ser ajustados numa correlação de valores onde o máximo econômico reflita igualmente um máximo ecológico" (DERANI, 2008, p. 128).

Na concepção de Garcia (2011) é impossível discutir a sustentabilidade econômica de forma dissociada da ambiental. Freitas (2012) ressalta que a pobreza, a miséria, a ausência de saneamento básico e tudo mais que comprometa a dignidade humana por ausência de recursos materiais mínimos à saudável qualidade de vida, não é sustentável.

A dimensão econômica da sustentabilidade visa ao desenvolvimento com a finalidade de gerar melhor qualidade de vida às pessoas. Passou a ser considerada no contexto da sustentabilidade porque não haveria possibilidade de retroceder nas conquistas de desenvolvimento alcançadas pela sociedade mundial, pois o desenvolvimento está interligado à dimensão social da sustentabilidade, sendo necessário para diminuir a pobreza da população.

Compreende na dimensão social da sustentabilidade, o capital humano, aspecto social relacionado às qualidades dos seres humanos. Baseia-se no processo de melhoria da qualidade de vida da sociedade, por meio da redução das discrepâncias entre a miséria e a opulência, bem como o nivelamento do padrão de renda, o acesso à educação, à moradia, à alimentação. Em suma, da garantia mínima dos direitos sociais constitucionalmente previstos.

Para Garcia (2011) a dimensão social implica em melhoria na qualidade de vida da coletividade, na redução da discrepância oriunda da injusta distribuição de renda, ligada à garantia dos direitos sociais e da dignidade da pessoa humana. Com lastro teórico nas grandes conferências globais sobre o meio ambiente, a referida autora sustenta que a pobreza é um dos grandes desastres da humanidade. Os privados do mínimo existencial à sua sobrevivência não têm garantido direitos sociais básicos do art. $6^{\circ}$ da CRFB/88. Negar a dignidade humana aos que vivem em extrema pobreza contribui para que depredem o meio ambiente (BRASIL, 1988).

Na concepção de Neves (2011, p. 17) "o conceito de sustentabilidade social caracterizase pela melhoria da qualidade de vida da população, equidade na distribuição de renda e de diminuição das diferenças sociais, com participação e organização popular".

Conforme o entendimento de Sachs (2009, p. 85-89) a dimensão social se refere ao "alcance de um patamar razoável de homogeneidade social, com distribuição de renda justa, emprego pleno e/ou autônomo com qualidade de vida decente e igualdade no acesso aos recursos e serviços sociais". O referido autor se refere à concretude dos direitos sociais.

Desta forma, a sustentabilidade visa a "atender as necessidades da geração presente e das futuras, de tal forma que o capital natural seja mantido e enriquecido em sua capacidade de regeneração, reprodução e coevolução" (BOFF, 2012, p. 107).

Para MEADOWS e RANDERS (2007) o rápido crescimento populacional e da produção industrial destaca a escassez dos recursos naturais e evidencia os limites da Terra e o modelo de vida insustentável. A consequência é o aumento global dos problemas ambientais, sociais e econômicos.

Destacam-se os seguintes problemas ambientais: a perda da biodiversidade; a superpopulação; o esgotamento dos recursos naturais; a manipulação genética; a contaminação e a escassez da água potável; a contaminação do ar e da terra; o aquecimento global com o 
aumento de erupções vulcânicas, do descongelamento das geleiras, a concentração de gases de efeito estufa, entre outros.

Representando os problemas sociais e econômicos, aumentou a pobreza, aumentaram as injustiças sociais; aumentaram os deslocados ambientais, aumentou a dependência tecnológica dos países em desenvolvimento para com os países desenvolvidos; aumentou a mortalidade infantil e piorou a educação formal.

Em nível mundial o aumento da pobreza é assustador. "Em média, 1,49 milhão de brasileiros vivem na pobreza extrema, que seriam as pessoas que vivem com até $R \$ 136,00$ mensais" (EFE, 2001).

Em 2019, no Relatório de Desenvolvimento Humano da Organização das Nações Unidas, "ainda existem no mundo 600 milhões de pessoas vivendo na extrema pobreza se considerado o parâmetro adotado pela ONU e pelo Banco Mundial de U\$ 1,90 (um dólar e noventa cents) por dia como linha da pobreza" (ONU, 2021).

Conforme o Índice Multidimensional da Pobreza, elaborado pela Oxford Poverty and Human Development Initiative da Universidade de Oxford e pelo Programa de Desenvolvimento das Nações Unidas "são 1,3 bilhão de pessoas vivendo em extrema pobreza" (ONU, 2021).

Fome, violência, desigualdades, crise econômica, miséria, anestesia ideológica, perda de referenciais, vazio individualista, diluição da família, perda dos espaços públicos, relativização dos comportamentos sociais, indiferença, cinismo social, consumismo... são os grandes desafios de nossos tempos (BITTAR, 2016, p. 83).

Retornando ao conceito de sustentabilidade como "o suficiente, para todos, em todos os lugares e sempre", conforme a definição completa retirada de uma variação em um grafite de um muro em Johannesburg, durante a Conferência Mundial sobre o desenvolvimento sustentável, realizada em 2002.

Trata-se da necessidade de consumir apenas o suficiente para a nossa vida, reduzir o consumo abusivo para garantir a sobrevivência de todas as formas de vida, em todos os lugares do mundo, para as presentes e as futuras gerações. Na concepção de Rifkin (2010) para que seja efetiva essa sustentabilidade é necessário uma consciência global para esse mundo em crise.

A sustentabilidade em sua dimensão ambiental destaca a importância da proteção do meio ambiente e consequentemente do direito ambiental, para garantir a sobrevivência no planeta de todas as espécies.

Na concepção de Garcia (2014, p. 20) a dimensão econômica da sustentabilidade visa à diminuição das externalidades negativas da produção, buscando por uma economia preocupada em gerar melhor qualidade de vida às pessoas. Há uma grande ligação entre a economia e o direito ambiental, eis que ambos visam à melhoria da qualidade de vida das pessoas para o alcance do desenvolvimento social, econômico e cultural.

Para Cruz e Real Ferrer (2015, p. 239) a dimensão tecnológica está ligada à inteligência humana individual e coletiva acumulada e multiplicada, que poderá garantir um futuro sustentável. Relaciona-se ao uso de novas tecnologias que sejam mais sustentáveis e menos impactantes ao ambiente.

Garcia (2020, p. 34) destaca que o debate da ética faz-se necessário porque o que se verifica na atualidade é a morte da ética tradicional. Logo, a dimensão ética da sustentabilidade aborda uma questão existencial. Busca garantir a vida, não estando simplesmente relacionado com a natureza, mas com toda a relação entre o indivíduo e o ambiente.

A temática central da pesquisa em testilha é a dimensão social da sustentabilidade, "é visto como capital humano e consiste no aspecto social relacionado com as qualidades dos seres humanos" (SOUZA; GARCIA, 2014, p. 37). 
Artigo: O Agravamento das Desigualdades Sociais na Pandemia Do Coronavírus Sars-Cov-2 e a Dimensão Social da Sustentabilidade

Trata-se de um processo de melhoria na qualidade de vida das pessoas, reduzindo as diferenças entre a miséria e a opulência, no sentido de nivelar o padrão de renda da população, bem como o acesso à moradia, à alimentação e à educação.

Representa o abrigo dos direitos fundamentais sociais. Não se admite um modelo de desenvolvimento excludente. Deve-se criar condições para a potencialização das qualidades humanas pela garantia de educação de qualidade e a busca de mecanismos de melhoria das condições de vida e dignidade de todos os seres humanos.

Consoante Garcia (2016, p. 95) visa a garantia do mínimo existencial que deve ser identificado como o núcleo sindicalizável da dignidade humana, incluindo como proposta para sua concretização os direitos à educação fundamental, à saúde básica, à assistência no caso de necessidade e ao acesso à justiça, todos exigíveis judicialmente de forma direta, eis que previstos na $\mathrm{CRFB} / 88$.

Para Sachs (2009, p. 85) são quatro os critérios da dimensão social da sustentabilidade, a saber: "a) o alcance de um patamar razoável de homogeneidade social; b) a distribuição de renda justa; c) emprego pleno e/ou autônomo com qualidade de vida decente; d) igualdade no acesso aos recursos e serviços sociais".

$\mathrm{Na}$ concepção de Rogers, Jalar e Boyd (2008, p. 219) a dimensão social da sustentabilidade apresenta dez subdimensões: redução da pobreza; desenvolvimento participativo; construção do consenso; organizações não governamentais; gênero e desenvolvimento; reassentamento involuntário; populações indígenas; exclusão social; análise social; desenvolvimento de indicadores sociais.

Para o alcance do desenvolvimento sustentável e o enfrentamento dos problemas ambientais é necessário reduzir a desigualdade social e o problema da falta de acesso, por grande parte da população, aos direitos sociais básicos. Sarlet e Fensterseifer (2011, p. 91) ressaltam que também representa um fator de aumento da degradação ambiental.

Na concepção de Garcia (2021, p. 215) "o mínimo existencial corresponde ao 'núcleo duro' dos direitos fundamentais, não podendo esses direitos serem alterados/retirados, pois haveria uma violação do princípio da dignidade humana". Assim, cada direito social corresponde à manutenção de um mínimo existencial.

Conforme o entendimento de Silva (2007, p. 26-27) o desenvolvimento sustentável tem como requisito indispensável um crescimento econômico, que envolva equitativa redistribuição dos resultados do processo produtivo e a erradicação da pobreza, para reduzir as disparidades nos padrões de vida da população. O referido autor explicar que, se o desenvolvimento não elimina a pobreza absoluta, não propicia um nível de vida que satisfaça as necessidades essenciais da população em geral, desta forma, não é sustentável.

Os direitos sociais básicos são condição mínima para que o ser humano reconheça nas normas da sociedade sua dignidade e se integre à comunidade. Deixar de garantir o mínimo existencial é excluir o ser humano da comunidade, significa negar sua condição política.

A proteção ambiental está ligada à garantia dos direitos sociais, eis que o gozo destes direitos sociais, tais como a moradia, a educação, a saúde, a alimentação, entre outros, está vinculado às condições ambientais favoráveis, como, por exemplo, o acesso a água potável, pelo saneamento básico, também considerado um direito fundamental social integrante do conteúdo mínimo existencial, bem como a alimentação sem a contaminação de agrotóxicos, a moradia em área que não poluída e sem riscos de desabamento.

Tanto a desigualdade social quanto a pobreza estão relacionadas à dimensão econômica da sustentabilidade e são protegidas pelo sócioambientalismo. Entretanto, os critérios de solidariedade serão necessários para mudar o modelo de pensamento liberal de crescimento.

Conforme o entendimento de Rogers, Jalar e Boyd (2008, p. 219) para o alcance do desenvolvimento sustentável, "dois círculos viciosos devem ser quebrados: o da pobreza e o do desenvolvimento. A pobreza causa um círculo vicioso de esgotamento e degradação 
ambiental". O esgotamento de recursos, a degradação e as mudanças climáticas retardam o desenvolvimento.

Para combater a pobreza e enfrentar os problemas sociais é necessário corrigir a desigualdade social e a falta de acesso da população pobre aos direitos sociais básicos. A degradação ambiental agrava estes problemas. O equilíbrio das dimensões da sustentabilidade para o alcance de um futuro sustentável necessita do combate á pobreza e do enfrentamento da desigualdade social.

A pandemia do novo Coronavírus, Sars-Cov-2, evidenciou o aumento do nível de desigualdade social e da pobreza. O combate ao Covid-19 não representa apenas uma questão econômica ou de saúde pública, ultrapassa o fechamento das fronteiras, o isolamento social e o fechamento do comércio e dos transportes. Trata-se de uma questão de relevância ainda maior, que precisará de esforços globais no sentido de reduzir as desigualdades sociais e garantir os direitos sociais em um mundo pós-pandêmico.

\section{AS DESIGUALDADES SOCIAIS NO CONTEXTO DA PANDEMIA DA COVID-19}

Uma sociedade solidária e sustentável depende da redução da desigualdade social, do combate à pobreza e da manutenção da qualidade de vida das pessoas. O novo Coronavírus, Sars-Cov-2, exigiu, para manutenção da sobrevivência das pessoas, várias medidas de proteção à saúde, bem como medidas políticas e econômicas, que acarretaram inúmeros problemas sociais, muitas vezes agravados pela falta de medidas, pela dificuldade em gerir as crises.

Os problemas sociais e econômicos aqui destacados não foram causados diretamente pelo novo Coronavírus, porém foram substancialmente por ele agravados. Desta forma, ficou evidente que a crise advinda da Covid-19 aumentou os problemas sociais e também ressaltou a desigualdade social no mundo. Para Kafruni (2021) a crise provocada pela pandemia evidenciou a fragilidade estrutural e aumentou as desigualdades sociais brasileiras, mostradas pela mídia.

Conforme os dados do IBGE de 2019 e o entendimento de Saito, Laques e Afelt (2020, p. 116), a pobreza monetária no Brasil se soma a precariedades e vulnerabilidades nas condições de moradia.

Segundo o estudo desenvolvido pela Pontifícia Universidade Católica do Rio Grande do Sul, por meio do Observatório das Metrópoles e pelo Observatório da Dívida Social na América Latina, sobre a desigualdade de renda do trabalho nas metrópoles brasileiras, apontou que:

\footnotetext{
Entre o final de 2019 e o segundo trimestre de 2020 ocorreu um grande aumento na referida desigualdade decorrente da crise econômica já vivenciada pelo Brasil e evidenciada no início de 2020 quando da divulgação do PIB referente a 2019 pelo IBGE, demonstrando uma desaceleração da economia no referido ano ante o crescimento de apenas $1,1 \%$ do PIB, que segundo o IBGE revelou a economia ainda no patamar de 2013, mas foi consideravelmente agravada pela pandemia da Covid-19 (PUCRS, 2020).
}

A referida pesquisa demonstrou que "para o conjunto das regiões metropolitanas do Brasil subiu de 0.603 no $4^{\circ}$ trimestre de 2019 , para 0.610 no $1^{\circ}$ trimestre de 2020 e, por fim, 0.640 no $2^{\circ}$ trimestre deste ano" (PUCRS, 2020). Representa um aumento de 6,1\% em apenas seis meses. Os dados da pesquisa apenas escancararam a desigualdade de renda vivenciada no país.

Segundo a pesquisa da PUCRS (2020) a pandemia do Covid-19 evidenciou uma queda de renda do trabalho, essa diminuição foi proporcionalmente maior entre os $40 \%$ mais pobres, que correspondem à base da pirâmide social. O conjunto dos $10 \%$ do topo, correspondentes aos 
Artigo: O Agravamento das Desigualdades Sociais na Pandemia Do Coronavírus Sars-Cov-2 e a Dimensão Social da Sustentabilidade

mais ricos, de cada região metropolitana, teve redução de $-3.2 \%$ em seus rendimentos, enquanto entre os mais pobres a queda foi $-32.1 \%$. Em algumas metrópoles, como São Paulo, se destaca a disparidade encontrada no último trimestre.

Sob a perspectiva racial o resultado da pesquisa é ainda mais assustador, considerando que a desigualdade racial tem se mostrado em nível ainda mais elevado que a média nacional.

Na concepção de Dowbor (2020) a realidade econômica brasileira em 2019 se agravou pelas diversas atuações políticas, a saber: congelamento do salário-mínimo e do Bolsa Família, perda de direitos trabalhistas, retrocesso na Previdência, teto de gastos, ataques às organizações da sociedade civil, bem como diversas medidas que travaram a renda e o acesso aos bens de consumo coletivo da maior parte da população, enquanto aumentou o lucro dos bancos e dos grandes investidores.

Para Garcia (2020, p. 67) chegamos à pandemia de 2020 com um Estado mínimo, com desigualdades sociais absurdas e com políticas que tiveram como diretrizes de destruição do Estado social de Direito. O referido autor se refere à "flexibilização de direitos trabalhistas, privatização da saúde, desconstitucionalização da previdência social, limitações de gastos públicos, além de ser um Estado desumanizado sem políticas públicas sociais" (GARCIA, 2020, p. 68). Trata-se de um Estado que serve somente às elites, com um povo manipulado que perdeu a capacidade de reagir.

Em relação ao trabalho no Brasil, o IBGE (2021) mostra o aumento de desemprego devido à pandemia do novo Coronavírus. São indicadores de trabalho, que durante o período de 20 a 26 de setembro de 2020 , refletiram em:

[...] 14,4\% a taxa de desocupação dos brasileiros; 2,7 milhões de pessoas afastadas do trabalho devido ao distanciamento social; 7,9 milhões de pessoas em trabalho remoto e 15,3 milhões de pessoas não procuram trabalho por conta da pandemia ou por falta de trabalho na localidade; 16,3 milhões de pessoas que tiveram rendimento efetivamente recebido menor do que o normalmente recebido (IBGE, 2021).

Os dados da pesquisa acima representam o aumento do desemprego e a diminuição da renda per capita. De acordo com a referida perspectiva, Martins (2020) destaca que as maiores vítimas da Covid-19 foram os trabalhadores temporários e sub-remunerados, que vivem de atividades informais, os desempregados e as pessoas vulneráveis e marginalizadas, que vivem nas ruas.

Desta forma, percebe-se que o novo Coronavírus impacta na dimensão social da sustentabilidade, pois prejudica a qualidade de vida dos brasileiros e agrava a desigualdade social. No sentido de manter a sustentabilidade é necessário visar ao equilíbrio das dimensões da sustentabilidade.

É necessária a "atuação do Estado para projetar confiança e reanimar a economia em tempos de crise e incerteza, investindo em programas de transferência de renda e concessão de empréstimos bancários subsidiados com baixas taxas de juros" (GUASQUE; GUASQUE, 2020, p. 259).

A pandemia do novo Coronavírus, Sars-Cov-2, agravou as desigualdades sociais e prolongou o caminho para uma sociedade sustentável, que será trilhado pela maior parte da população mundial "com muita dor, angústia e sofrimento, o que não é só eticamente como economicamente incoerente, já que o equilíbrio entre os vieses econômicos e sociais é necessário para o real desenvolvimento econômico" (SACHS, 2005, p. 58).

É inaceitável a desigualdade social inaceitável desde o ponto de vista político e ético. O Estado não deve consentir os resultados dos mercados competitivos como algo predeterminado e imutável.

O Estado precisa reagir às adversidades dos momentos de crise, como a que vivemos em razão do novo Coronavírus, Sars-Cov-2. Desta forma, urge adotar medidas para corrigir a 
distribuição da renda, por meio de transferências monetárias a indivíduos desfavorecidos, ou de impostos progressivos, por exemplo.

\section{CONSIDERAÇÕES FINAIS}

Atualmente, a sustentabilidade representa um meio e um fim em si mesma, decorrente do equilíbrio de algumas dimensões capazes de garantir a digna continuação de vida no planeta.

A pesquisa em testilha apontou que a doutrina não é uníssona ao delimitar as dimensões da sustentabilidade, porém a referida pesquisa utilizou o tripé dimensional, ou seja, enfatizou as dimensões ambiental, econômica e social da sustentabilidade, sem esquecer-se de elencar também a existência das dimensões ética e tecnológica. Em relação à temática abordada, a dimensão social da sustentabilidade ganhou maior destaque.

Para o alcance da sociedade solidária e sustentável, é necessário e urgente o equilíbrio equânime entre as dimensões da sustentabilidade, porque uma dimensão não compensa a outra, são diferentes.

As desigualdades sociais afetam diretamente a dimensão social da sustentabilidade, estruturada na redução das diferenças entre a miséria e a opulência, com o nivelamento do padrão de renda, acesso à moradia, à alimentação, à educação e baseada na melhoria da qualidade de vida da sociedade. As referidas desigualdades sociais envolvem problemas complexos com repercussão mundial, conforme os estudos analisados na pesquisa em testilha.

Ocorre que o novo Coronavírus, Sars-Cov-2, tratado no tópico 2 da pesquisa em tela, pela própria característica da pandemia do Covid-19 e pela emergência de saúde pública que representa, exigiu, para a manutenção da sobrevivência das pessoas, a utilização de várias medidas proteção à saúde. As referidas medidas não visam proteger apenas a saúde pública, mas também representam medidas econômicas e políticas, que acarretaram e/ou agravaram inúmeros outros problemas sociais, porque não ocorreu a concretização das referidas medidas, ou pela falta de apresentação de medidas, de políticas públicas de saúde e economia, ou ainda e pelo descaso político em gerenciar as crises acarretadas ou agravadas pelo novo Coronavírus.

Portanto, para alcançar o almejado futuro sustentável, é urgente e necessário o equilíbrio das dimensões da sustentabilidade, inevitavelmente por meio do combate à pobreza e do enfrentamento da desigualdade social mundial.

O combate à pandemia do novo Coronavírus, Sars-Cov-2, não significa simplesmente resolver as questões de saúde pública, determinar o isolamento da população, o fechamento do comércio, dos serviços, proibir a circulação de pessoas e de veículos, fechar as fronteiras, ou as questões econômicas. Necessariamente ultrapassa todas essas questões e exige um enorme esforço mundial para reduzir as desigualdades sociais e garantir os direitos sociais em um mundo pós-pandêmico.

\section{REFERÊNCIAS}

BBC NEWS. Coronavírus: OMS declara pandemia, 11 mar. 2020. Disponível em: www.bbc.com/portuguese/geral-51842518. Acesso em: 3 ago. 2021.

BITTAR, Eduardo C. B. Curso de ética jurídica: ética geral e profissional. 13. ed. São Paulo: Saraiva, 2016.

BOFF, Leonardo. Sustentabilidade: o que é - o que não é. Petrópolis-RJ: Vozes, 2012.

BOSSELMANN, Klaus. O princípio da sustentabilidade: transformando direito e 
Artigo: O Agravamento das Desigualdades Sociais na Pandemia Do Coronavírus Sars-Cov-2 e a Dimensão Social da Sustentabilidade

governança. Tradução de Phillip Gil França. São Paulo: RT, 2015.

CANOTILHO, Joaquim José Gomes. O princípio da sustentabilidade como princípio estruturante do Direito Constitucional. Revista de Estudos Politécnicos, v. 8, n. 13, 2010. Disponível em: http://www.scielo.oces.mctes.pt/ pdf/tek/n13/n13a02. Acesso em: 16 jul. 2019.

COIMBRA, Wilber Carlos dos Santos. A tutela da sustentabilidade exercida pelos Tribunais de Contas como garantia de efetividade dos atos da Administração Pública. Tese (Doutorado em Ciência Jurídica). Curso de Doutorado em Ciência Jurídica, Universidade do Vale do Itajaí, Santa Catarina, 2017.

COSTA, Ligia Maria Cantarino da; HAMANN, Edgar Merchan. Pandemias de influenza e a estrutura sanitária brasileira: breve histórico e caracterização dos cenários. Revista PanAmoz Saúde, v. 7, n. 1, p. 11-25, 2016.

CRUZ, Paulo Márcio; BODNAR, Zenildo. Globalização, transnacionalidade e sustentabilidade. In: CRUZ, Paulo Márcio; BODNAR, Zenildo; REAL FERRER, Gabriel;

PRADO, Lucas de Melo (Orgs.). Livro eletrônico. Itajaí-SC: UNIVALI, 2012. Disponível em: http://www.univali.br/ppcj/ebook. Acesso em: 19 jul. 2019.

CRUZ, Paulo Márcio; GLASENAPP, Maikon Cristiano. Governança e sustentabilidade: constituindo novos paradigmas na pós-modernidade. Revista Direito e Liberdade, Natal, v. 16, n. 2, p. 163-186, mai./ago., 2014.

CRUZ, Paulo Márcio; REAL FERRER, Gabriel. Direito, sustentabilidade e a premissa tecnológica como ampliação de seus fundamentos. Sequência (UFSC), v. 36, p. 239-278, 2015.

DERANI, Cristiane. Direito ambiental econômico. 3. ed. São Paulo: Saraiva, 2008.

DOWBOR, Ladislau. Além do coronavírus. Le Monde Diplomatique Brasil, 7 abr. 2020. Disponível em: https://diplomatique.org.br/alem-do-coronavirus/. Acesso em: 3 ago. 2021. EFE. Mais de 113 milhões de pessoas foram vítimas de fome extrema em 2018. Exame, 2 abr. 2019. Disponível em: https://exame.com/mundo/mais-de-113-milhoes-de-pessoas-foramvitimas-de-fome-extrema-em-2018/. Acesso em: 2 ago. 2021.

EFE. OMS: mundo tem 1,52 milhão de casos da COVID 19 e 92,5 mil mortes. R7, 10 de abr. de 2020. Disponível em: https://noticias.r7.com/saude/omsmundo-tem-152-milhao-de-casosda-covid-19-e-925-mil-mortes-10042020. Acesso em: 3 ago. 2021.

FENSTERSEIFER, Tiago. Direitos fundamentais e proteção ambiental: a dimensão ecológica da dignidade humana no marco jurídico-constitucional do Estado Socioambiental de Direito. Porto Alegre: Livraria do Advogado, 2006.

FREITAS, Juarez. Sustentabilidade: direito ao futuro. 2. ed. Belo Horizonte: Fórum, 2012.

FREITAS, Thiago Pereira de. Sustentabilidade e as contratações públicas. Rio de Janeiro: Lumen Juris, 2014. 
GARCIA, Denise Schmitt Siqueira. A busca por uma economia ambiental: a ligação entre o meio ambiente e o direito econômico. In: GARCIA, Denise Schmitt Siqueira (Org.).

Governança transnacional e sustentabilidade. Itajaí: Univali, 2014. v. 1, p. 7-27.

GARCIA, Denise Schmitt Siqueira. Dimensão Econômica da Sustentabilidade: uma análise com base na economia verde e a teoria do decrescimento. Veredas do Direito, v. 13, p. 133$153,2016$.

GARCIA, Denise Schmitt Siqueira. El principio de sostenibilidad y los puertos: a atividade portuária como garantidora da dimensão econômica e social do princípio da sustentabilidade. 2011. $451 \mathrm{f}$. Tese. (Doctorado em Derecho Ambiental y Sostenibilidad de la Universidad de Alicante - UA). Espanha, Universidade de Alicante, 2011.

GARCIA, Denise Schmitt Siqueira. Uma nova perspectiva para o direito ambiental: o direito ao ambiente como direito fundamental da pessoa humana. Interesse Público (Impresso), v. 18, p. 95-110, 2016.

GARCIA, Denise Schmitt Siqueira; GARCIA, Heloise Siqueira. Dimensão social do princípio da sustentabilidade: uma análise do mínimo existencial ecológico. In:

SOUZA, Maria Claudia da Silva Antunes de; GARCIA, Heloise Siqueira (Org.).

Lineamentos sobre sustentabilidade segundo Gabriel Real Ferrer. Itajaí: Univali, 2014. v. 1, p. 37-54.

GARCIA, Denise Schmitt Siqueira; GARCIA, Heloise Siqueira. Ethical dimension of sustainability: the need to change values and attitudes. Sostenibilidad: económica, social y ambiental (EcosUA), Alicante, n. 2, p. 33-47, 2020.

GARCIA, Denise Schmitt Siqueira; GARCIA, Heloise Siqueira; CRUZ, Paulo Márcio. Dimensão social da sustentabilidade e a pandemia da Covid-19: uma análise das desigualdades sociais. Revista Direito Administrativo, Rio de Janeiro, v. 280, n. 1, p. $207-$ 231, jan./abr. 2021.

GARCIA, Marcos Leite. Reflexões sobre a pandemia da covid-19: algumas lições para o futuro. In: PILAU SOBRINHO, Liton Lanes (Org.) Paradigmas da sociedade contemporânea: reflexos das pandemias. Itajaí: Univali, 2020.

GUASQUE, Adriane; GUASQUE, Bárbara. A pandemia e o necessário e tempestivo retorno aos matizes keynesianos. Opinión Jurídica, v. 19, n. 40, ed. especial 2020, p. 259-276, 2020.

IBGE. O IBGE apoiando o combate à Covid-19. Trabalho: desocupação, renda, afastamento, trabalho remoto e outros efeitos da pandemia no trabalho. Disponível em: https://covid19.ibge.gov.br/pnad-covid/trabalho.php. Acesso em: 3 ago. 2021.

IBGE. Síntese de indicadores sociais: uma análise das condições de vida da população brasileira 2019. Rio de Janeiro: IBGE, 2019. (Estudos e Pesquisas Informação Demográfica e Socioeconômica número 40). Disponível em: https://biblioteca.ibge.gov.br/visualizacao/livros/liv101678.pdf. Acesso em: 29 jul. 2021. 
Artigo: O Agravamento das Desigualdades Sociais na Pandemia Do Coronavírus Sars-Cov-2 e a Dimensão Social da Sustentabilidade

JAMIESON, Dale. Ética e meio ambiente: uma introdução. Tradução de André Luiz de Alvarenga. São Paulo: SENAC, 2010.

KAFRUNI, Simone. Desigualdade que envergonha: crise da Covid-19 ampliará problemas sociais. Correio Braziliense, 20 abr. 2020. Disponível em:

www.correiobraziliense.com.br/app/noticia/economia/2020/04/20/internas_economia,846332/ desigualdade-que-envergonha-crise-da-covid-19-ampliaraproblemas-soci.shtml. Acesso em: 3 ago. 2021.

MARTINS, Mônica Dias. A pandemia expõe de forma escancarada a desigualdade social. Clacso - Consejo Latinoamericano de Ciencias Sociales. Texto apresentado em videoconferência sobre o tema Pandemia, Demografia e Desigualdade Social, promovida pela Secretaria de Ciência, Tecnologia e Educação Superior do Estado do Ceará (Secitece), em 21 abr. 2020. Disponível em: www.clacso.org/a-pandemia-expoe-de-forma-escancarada-adesigualdade-social/. Acesso em: 3 ago. 2021.

MEADOWS, Dennis L.; RANDERS, Jorgen; MEADOWS, Donella H. Limites do crescimento. A atualização de 30 anos. Rio de Janeiro: FGV, 2007.

NEVES, Lafaite Santos. Sustentabilidade: anais de textos selecionados do $5^{\circ}$ seminário sobre sustentabilidade. Curitiba-PR: Juruá, 2011.

ONU. Human development report 2019. Beyond income, beyond averages, beyond today: inequalities in human development in the 21st century. Nova York, 2019. Disponível em: http://hdr.undp.org/sites/default/files/hdr2019.pdf. Acesso em: 29 jul. 2021.

ONU Brasil. Transformando nosso mundo: a Agenda 2030 para o Desenvolvimento Sustentável. Disponível em: https://nacoesunidas.org/pos2015/agenda2030/. Acesso em: 30 jul. 2021.

ORGANIZAÇÃO DAS NAÇÕES UNIDAS. A ONU e a população mundial. Disponível em: https://nacoesunidas.org/acao/populacao-mundial/. Acesso em: 8 abr. 2020.

ORGANIZAÇÃO MUNDIAL DA SAÚDE. Regulamento sanitário internacional. 3. ed. 2005. Disponível em:

https://apps.who.int/iris/bitstream/handle/10665/246186/9789243580494-

spa.pdf;jsessionid=98D14572D164AEE5E25FEAE462226FF4? sequence $=1$. Acesso em: 3 ago. 2021.

ORGANIZAÇÃO PAN-AMERICANA DE SAÚDE. Folha informativa - Covid-19 (doença causada pelo novo coronavírus). Brasília, 8 abr. 2020. Disponível em: www.paho.org/bra/index.php?option=com_content $\&$ view=article \&id=6101 $:$ covid19\&Itemid $=875$. Acesso em: 30 jul. 2021.

PASOLD, Cesar Luis. Prática da pesquisa jurídica e metodologia da pesquisa jurídica. Florianópolis: OAB/SC Editora, 2007.

PUCRS. Desigualdade social cresce nas metrópoles brasileiras durante a pandemia. PUCRS, 20 out. 2020. Disponível em: www.pucrs.br/blog/desigualdade-social-cresce-nas-metropolesbrasileiras-durante-a-pandemia/. Acesso em: 29 jan. 2021. 
REAL FERRER, Gabriel. Calidad de vida, medio ambiente, sostentabilidad y cidadanía. Construímos juntos el futuro? Revista Novos Estudos Jurídicos - NEJ, Itajaí-SC, v. 17, n. 3, p. 310-326, set./dez., 2012. Disponível em:

http://siaiweb06.univali.br/seer/index.php/nej/article/view/4202. Acesso em: 21 jul. 2019.

RIFKIN, Jeremy. La civilización empática. La carrera hacia una conciencia global en un mundo en crisis. Madri: Paidós, 2010.

ROGERS, Peter P.; JALAR, Kazi F.; BOYD, John A. An introduction to sustainable development. Londres: Earthscan, 2008.

SACHS, Ignacy. Caminhos para o desenvolvimento sustentável. Rio de Janeiro: Garamond, 2009.

SACHS, Ignacy; VIEIRA, Paulo Freire (Org.). Rumo à Ecossocioeconomia. Teoria e Prática do Desenvolvimento. São Paulo: Cortez, 2007.

SACHS, Jeffrey. O fim da pobreza: como acabar com a miséria mundial nos próximos vinte anos. Tradução de Pedro de Maia Soares. São Paulo: Companhia das Letras, 2005.

SAITO, Carlos Hiroo; LAQUES, Anne-Elisabeth; AFELT, Aneta. O mundo após o covid-19: vulnerabilidades, incertezas e desafios socioambientais. In: PILAU SOBRINHO, Liton Lanes;

CALGARO, Cleide; ROCHA, Leonel Severo (Org.). Covid-19 e seus paradoxos. Itajaí: Univali, 2020.

SARLET, Ingo Wolfgang; FENSTERSEIFER, Tiago. Direito constitucional ambiental. Estudos sobre a constituição, os direitos fundamentais e a proteção do ambiente. São Paulo: Revista dos Tribunais, 2011.

SILVA, José Afonso. Direito ambiental constitucional. São Paulo: Malheiros, 2007.

UJVARI, Stefan Cunha. Pandemias: a humanidade em risco. São Paulo: Contexto, 2011. 